\title{
The formulation and evaluation of culinary success factors (CSFs) that determine the palatibility of food
}

Citation for published version (APA):

Klosse, P., Riga, J., Cramwinckel, A. B., \& Saris, W. H. M. (2004). The formulation and evaluation of culinary success factors (CSFs) that determine the palatibility of food. Food Service Technology, 107-115. https://doi.org/10.1111/j.1471-5740.2004.00097.x

Document status and date:

Published: 01/01/2004

DOI:

10.1111/j.1471-5740.2004.00097.x

Document Version:

Publisher's PDF, also known as Version of record

\section{Please check the document version of this publication:}

- A submitted manuscript is the version of the article upon submission and before peer-review. There can be important differences between the submitted version and the official published version of record.

People interested in the research are advised to contact the author for the final version of the publication, or visit the DOI to the publisher's website.

- The final author version and the galley proof are versions of the publication after peer review.

- The final published version features the final layout of the paper including the volume, issue and page numbers.

Link to publication

\footnotetext{
General rights rights.

- You may freely distribute the URL identifying the publication in the public portal. please follow below link for the End User Agreement:

www.umlib.nl/taverne-license

Take down policy

If you believe that this document breaches copyright please contact us at:

repository@maastrichtuniversity.nl

providing details and we will investigate your claim.
}

Copyright and moral rights for the publications made accessible in the public portal are retained by the authors and/or other copyright owners and it is a condition of accessing publications that users recognise and abide by the legal requirements associated with these

- Users may download and print one copy of any publication from the public portal for the purpose of private study or research.

- You may not further distribute the material or use it for any profit-making activity or commercial gain

If the publication is distributed under the terms of Article $25 \mathrm{fa}$ of the Dutch Copyright Act, indicated by the "Taverne" license above, 


\title{
The formulation and evaluation of culinary success factors (CSFs) that determine the palatability of food
}

\author{
P. R. Klosse, ${ }^{\ddagger}$ J. Riga, ${ }^{*}$ A. B. Cramwinckel, ${ }^{\dagger}$ and W. H. M. Saris ${ }^{\ddagger}$ \\ *Academy for Gastronomy, Amersfoortseweg, Hoog Soeren, the Netherlands; ${ }^{\dagger}$ Centrum voor Smaakonderzoek, Agro \\ Business Park, Wageningen, the Netherlands; and ${ }^{\ddagger}$ Nutrition Research Institute Maastricht, NUTRIM, University of \\ Maastricht, Maastricht, the Netherlands
}

Correspondence:

P. R. Klosse, Academy for Gastronomy,

Amersfoortseweg 86, 7346

AA Hoog Soeren, the

Netherlands.

Tel: 3155 5191429;

Fax: 3155 5191047;

E-mail: p.klosse@echoput.nl

Keywords:

culinary success factors, flavour, food, palatability, product development, taste

\begin{abstract}
The aim of the research reported here was to analyse palatability. In the first part of the study, renowned chefs in the Netherlands were interviewed about their most successful dishes to search for 'common denominators'. In total 18 chefs were interviewed and 63 dishes were analysed. Six product characteristics were found that were present in at least $80 \%$ of the described dishes: (i) name and presentation fit the expectation; (ii) appetizing smell that fits the food; (iii) good balance of flavour components in relation to the food; (iv) presence of umami, also called the fifth basic taste; (v) in mouthfeel a mix of hard and soft textures; and (vi) high flavour richness. It was hypothesized that palatability is determined by the presence of each of these culinary success factors (CSFs). In a second study, a Michelin-star chef was asked to develop three series of dishes each with a specified main ingredient. Every series consisted of one dish based on the CSFs and two variants, in which systematically one of the CSFs was left out, under the condition that the dish was still restaurantworthy. In a tasting these nine dishes were served to a group of 26 experienced restaurant guests. In the tasting, the dishes in which most CSFs were united were preferred to the variants. It is concluded that the formulated CSFs can help chefs in the development of new dishes and improvement of existing ones.
\end{abstract}

\section{Introduction}

Palatability is defined as flavours that are pleasing to the palate and is brought about by a successful combination of product qualities (The Monell Connection 2000). Flavour and palatability are important drivers of liking, and, consequently, palatability is closely related to liking. However, both concepts are quite different and it is functional to distinguish the two concepts. Liking is defined as an affective human response to a certain food or drink. This implies that palatability is product-related while liking is related to what humans think of the product (The Monell Connection 2000). This raises the question of whether liking must be considered as a coincidence, happening haphazardly or as the predictable outcome when certain product qualities are present. It was hypothesized that there must be factors that determine palatability and that such factors are critical for the potential success of food products. Once such culinary success factors (CSFs) are defined, they could be used in product development to evaluate the potential success of new products or in the improvement of existing ones.

Food is available in an infinite variety, based on all kinds of ingredients, and produced both industrially and according to traditional methods, in commercial restaurants or at home. In studying palatability a choice has to be made of the products to be analysed. The popularity of commercial food products could be a criterion. Some well-known food products are a success throughout the world and it is hard to imagine that they are not found to be palatable. However, advertising is crucial in this highly competitive industry and com- 
mercial success of these products is highly influenced by it. Therefore, it was decided not to choose popular industrial foods that are consumed on a large scale.

As objects of our study, restaurant dishes were chosen that have been on the menu for quite some time and are prepared by well-known chefs, many of whom have been awarded one or more Michelin stars. This focus was chosen because these dishes are known to be palatable, while their popularity is hardly influenced by marketing forces. Yet the popularity of these dishes is such that they have to stay on the menu so as not to disappoint the people that have come especially to savour them. Most of the best restaurants in any country have at least a few of such dishes. We suppose these dishes must have something special and possibly could have 'common denominators', collective qualities that make them special.

There is quite another argument for using these dishes as a starting point. Flavour research generally takes place in laboratories. Results based on studies in laboratory settings, be it on specific components, like salt or bitter, or on tests using animals, are in general not easily applicable in daily life (Cardello et al. 2000). Consequently, some of the strategies employed in laboratory research produce results that are valid for the laboratory but miss essential variables that make the difference between the laboratory and the real world. According to De Castro (2000) naturalistic research settings are better in that respect, but they give the researcher less control. He qualifies the high degree of control that characterizes the laboratory setting as both its virtue and its curse. Conclusions found in natural settings are likely to be trustworthy, if they have been derived carefully (Abdi 2002).

The research presented here involved two studies. The first entailed an inventory of dishes from highly ranked restaurants that have proven to be palatable in practice. The aim of this first study was to search for common denominators in these dishes whereupon factors could be formulated which supposedly determine palatability. As these factors are supposed to be critical to success, they are called culinary success factors (CSFs). In the second study the formulated CSFs were evaluated in a tasting. We hypothesized that the CSFs determine the palatability of dishes and that, consequently, the CSF dishes would be preferred over the others, with higher marks for palatability.

\section{Materials and methods}

\section{Study 1}

Eighteen of the best Dutch chefs (Table 1) were interviewed about their most successful dishes, defined as
Table 1 Chefs interviewed and their rating in the Michelin Guide 2002 (Michelin 2002)

\begin{tabular}{lc}
\hline Michelin rating & No. of chefs \\
\hline star & 5 \\
1 star & 10 \\
2 stars & 2 \\
3 stars & 1 \\
Total chefs interviewed & 18 \\
\hline
\end{tabular}

being popular and having been on the menu for at least three years. Sixty-three dishes were fully described, including the recipe and its flavour profile. Additional information was given on seasonality, regionalism, and price. The nature of the interviews allowed for the introduction of aspects that were considered important by the chefs. There was ample opportunity for chefs to give their views on the palatability of their dishes. On average the interviews lasted $1.5 \mathrm{~h}$. Appendix I shows the open questions that were asked about each dish. The interviews were all conducted by the same person who was trained in the concept of profiling flavour using the flavour styles cube (P.R. Klosse, A.B. Cramwinckel, F. Schevers, W.H.M. Saris, unpublished).

The authors analysed the interviews in committee to establish if there were factors in common. No specific statistical techniques or methods were used. As the objective was to formulate CSFs that can be applied generally, there was no specific interest in the ingredients used, that is at the micro level. In the analysis the interest was on the macro level. The flavour profiles were studied, and other factors that successful dishes might have in common. For a factor to be accepted as a CSF it was decided that it should be present in at least $80 \%$ of the dishes described, thus in at least 50 out of the 63 dishes analysed.

\section{Study 2}

After having formulated the CSFs, verification was the aim of the second part of our research. Can a professional chef create dishes using the CSFs, and if so - are these dishes considered to be more palatable than other dishes? A Michelin-star chef composed three dishes based on all the CSFs. Two variants were made of each dish in which systematically one CSF was changed under the condition that the variant was still worthy of being served in a top restaurant. Different main ingredients were used: prawn, turbot, and beef.

In a tasting session in a restaurant the three dishes and their alternatives were presented to experienced restaurant guests and evaluated. The subjects received 
a general invitation to participate in a tasting; the purpose of the tasting and the CSFs were not explained until after the tasting. The tasting took place in restaurant off-hours and subjects paid a small amount just to cover the expenses. Plates were unmarked and the tasters were given no other indications. The CSF dish and the two variants were served simultaneously. As a first course the three prawn dishes were presented, then the three turbot dishes and finally the three beef dishes. After every course the guests were asked to note their preference for one of the three variants of the dish and to give a mark for it. Differences in preference and palatability were tested. Appendix II shows the form that was used in the tasting.

Twenty-six individuals (14 male, 12 female, average age 47) participated in the tasting with no other instruction than to give their preference and to score the palatability of each dish on a scale from 1 (= low) to 10 (= high). One form of the first course was invalid and discarded. The probability of the order of preference in each course was analysed by Pearsons chisquare. The variance (ANOVA) of the results was calculated.

\section{Results}

\section{Results study 1: culinary success factors}

In the analysis of the described dishes six common qualities were found.

\section{Factor 1: name and presentation fit the expectation}

The description of the dishes conveyed adequately what to expect; no false expectations are raised. During the years, the name and presentation of the dishes were not changed, except for minor adjustments and improvements. The main ingredient is clearly visible and in general the presentation is pleasing and appetizing. Evidently, the flavour should always be the same. If the recipe changes drastically, the name should change as well.

\section{Factor 2: appetizing smell that fits the food}

Smell is an important driver of palatability. Just as there are bad smells that can prevent one from eating, there are attractive good smells. Chefs mentioned specifically the importance of those attractive odours, but also that off-flavours should not to be present. Palatability increases if smell and taste fit together.

\section{Factor 3: good balance in flavour components in} relation to the food

In palatable foods the flavour components are well balanced, never too sweet, salty, acidic, bitter, or ripe.
'Too ripe' was also mentioned as a potential disturber. To illustrate: meat that has been baked or grilled too long, bread that has been toasted too long, French fries that have been fried too long or a wine that has been aged in a wooden cask too long. In every one of these cases, ripe flavour notes prevail, while taking away the original flavours; the complexity of the flavour diminishes.

\section{Factor 4: presence of the umami}

In analysis, it was striking to see how often natural ingredients were used that are rich in glutamate acid or fermented products that acquire glutamate in the process. In Table 2 the ingredients of successful dishes related to umami are listed.

\section{Factor 5: combination of hard and soft textures}

The chefs often mentioned looking for a contrast in mouthfeel, with a combination of hard and soft textures. The combination of 'crispy' or 'crunchy' on one side and 'juicy', 'creamy', or 'moist' on the other seems crucial in palatability.

\section{Factor 6: flavour richness is high}

The last factor that was identified from the interviews was a high flavour richness of the dishes. Within flavour richness 'flavour intensity' and 'ripe' were the factors that characterized the flavour of palatable dishes.

\section{Results study 2: evaluation of CSF concept}

It was hypothesized that dishes based on these CSFs were palatable, and preferred over other dishes, and

Table 2 Examples of ingredients contributing to umami flavour (Ninomiya 1998; Yoshida 1998)

\begin{tabular}{ll}
\hline Natural ingredients & Fermented/aged products \\
\hline Tomato & Soy sauce \\
Corn & Oyster sauce \\
Spinach & Aged cheese (Parmesan) \\
Onion & Emmentaler cheese \\
Carrot & Cured ham \\
Mushroom (all kinds) & Broth \\
Green pea & Stock \\
Green asparagus & 'Glace de viande' \\
Scallop & Marmite \\
Alaska king crab & Trassi \\
Cod & \\
Salmon & \\
Chicken meat & \\
Milk/cream & \\
Eggs &
\end{tabular}


Table 3 Tasting results: prawn dishes

\begin{tabular}{|c|c|c|c|c|c|}
\hline & \multirow[b]{2}{*}{ Type } & \multicolumn{3}{|c|}{ Preference } & \multirow{2}{*}{$\begin{array}{l}\text { Total judgment } \\
(0-10)\end{array}$} \\
\hline & & $1 \mathrm{st}$ & $2 n d$ & $3 \mathrm{rd}$ & \\
\hline $\begin{array}{l}\text { Fried prawn with Noilly Prat sauce and lobster oil, } \\
\text { potato mousseline and green asparagus }\end{array}$ & CSF & 15 & 9 & 1 & 8.2 \\
\hline $\begin{array}{l}\text { Warm carpaccio of prawn with saffron-potato, } \\
\text { slices of asparagus and lobster oil }\end{array}$ & Variant 1 & 2 & 7 & 16 & 6.4 \\
\hline $\begin{array}{l}\text { Grilled prawn with lobster sauce, morels, saffronated } \\
\text { potato mousseline }\end{array}$ & Variant 2 & 8 & 9 & 8 & 7.4 \\
\hline Significance (count $n=25$ ) & & \multicolumn{3}{|c|}{ Pearsons chi-square $P<0.01$} & ANOVA $P<0.01$ \\
\hline
\end{tabular}

Table 4 Tasting results: turbot dishes

\begin{tabular}{|c|c|c|c|c|c|}
\hline & \multirow[b]{2}{*}{ Type } & \multicolumn{3}{|c|}{ Preference } & \multirow{2}{*}{$\begin{array}{l}\text { Total judgment } \\
(0-10)\end{array}$} \\
\hline & & 1 st & 2nd & 3 rd & \\
\hline $\begin{array}{l}\text { Sautéed turbot with aniseed-mushrooms, and } \\
\text { chanterelles, braised shallots, celeriac chips and truffle } \\
\text { sauce }\end{array}$ & CSF & 13 & 9 & 4 & 8.0 \\
\hline $\begin{array}{l}\text { Sautéed turbot with aniseed-mushrooms and a mousse } \\
\text { of shallots, celeriac and chanterelles }\end{array}$ & Variant 1 & 4 & 11 & 11 & 7.0 \\
\hline $\begin{array}{l}\text { Sautéed turbot with mousse of fennel, braised } \\
\text { fennel, aniseed-mushrooms, shallots and fennel sauce }\end{array}$ & Variant 2 & 9 & 6 & 11 & 7.3 \\
\hline Significance (count $n=26$ ) & & \multicolumn{3}{|c|}{ Pearsons chi-square $P<0.05$} & ANOVA $P<0.05$ \\
\hline
\end{tabular}

Table 5 Tasting results: beef dishes

\begin{tabular}{|c|c|c|c|c|c|}
\hline & \multirow[b]{2}{*}{ Type } & \multicolumn{3}{|c|}{ Preference } & \multirow{2}{*}{$\begin{array}{l}\text { Total judgment } \\
(0-10)\end{array}$} \\
\hline & & 1 st & 2nd & $3 \mathrm{rd}$ & \\
\hline Roasted fillet 'Rossini' & CSF & 20 & 4 & 2 & 8.2 \\
\hline $\begin{array}{l}\text { Poached fillet with goose liver, fried } \\
\text { egg and vegetables }\end{array}$ & Variant 1 & 3 & 11 & 12 & 6.3 \\
\hline $\begin{array}{l}\text { Tartare of fillet with goose liver and } \\
\text { poached egg }\end{array}$ & Variant 2 & 3 & 11 & 12 & 6.6 \\
\hline Significance (count $n=26$ ) & & \multicolumn{3}{|c|}{ Pearsons chi-square $P<0.001$} & ANOVA $P<0.001$ \\
\hline
\end{tabular}

implicitly, that a professional chef can create successful dishes with these CSFs. The CSF dishes and the variants were designed to be served in a Michelin-star restaurant and to be tasted by people that visit such restaurants. Tables 3, 4 and 5 show the scores for the respective dishes.

\section{Prawn variations}

Table 3 shows the prawn dishes that were designed.

In the CSF dish, the prawn was clearly visible, the flavour components were well balanced, the dry tex- ture of the prawn was compensated with the potato mousseline and the lobster oil, the colour of which was added to the overall presentation. Umami was present in the form of the prawns themselves and green asparagus.

In variant 1 , the principal change is the structure of the prawn which was sliced and presented like a carpaccio. The potato mousseline was changed to potatoes cut in small balls. Both changes gave a change in mouthfeel, the mix of hard and soft textures was partly lost. 
In variant 2 , adding ripe tones coming from morels and the grilling of the prawns had a negative effect on the flavour balance. Ripe flavours dominated the flavour profile. Yet the dish was still liked, although the CSF dish was preferred.

The results of the tasting showed a preference for the CSF dish. It was preferred by 15 tasters, while $87 \%$ of the tasters scored it as 8 or higher, resulting in a palatability score of 8.2. One response was not valid and was excluded $(n=25)$.

\section{Turbot variations}

In this course the main ingredient was kept exactly the same in all three dishes. The CSF dish was designed to be complex with ripe tones from truffle, mushrooms and the celeriac chips. All CSF factors were present.

In variant 1 the mousse of shallots added a characteristic sweet flavour to the dish that did not match well with the other flavours, impairing the flavour balance and partly expectation as sweetness was not to be expected.

In variant 2 the fresh tones from fennel replaced the ripe tones of the CSF dish.

The results show that the CSF dish and the two variants scored high in palatability $(8.0,7.0$, and 7.3 respectively, see Table 4). Yet the CSF dish was preferred by the majority. The result for variant 2 may be positively influenced by situational conditions that may have influenced this result, as the tasting was held in the afternoon of a relatively warm day $\left(25^{\circ} \mathrm{C}\right)$; circumstances in which fresh flavours are instinctively liked.

\section{Beef variations}

In the final course the classical name for the CSF dish 'Beef Rossini' was used. It stands for a pan-fried fillet topped with goose-liver and a fried quail-egg. This is a traditional dish that has been sustained over time and, not surprisingly, the CSFs are all present. Interestingly, after the tasting, some of the tasters remarked that the classical name gave them a negative impulse, which turned to positive in tasting the dish.

In variant 1 the same ingredients are used as in the CSF dish, but the fillet is not pan-fried, but poached at a low temperature in a strong beef stock. Tenderness and flavour are there, but in mouthfeel it lacks the bite of the crust of the roast, the odour of the Maillard effect and the ripe flavour notes.

In variant 2 the same ingredients were used as well, but the tartare was served at room temperature (as it should) and overall flavour richness was not as high as in the other dishes.
The results (Table 5) show that the CSF dish was found to be very palatable (score 8.2 ) and preferred by 20 tasters over the variants.

\section{Discussion}

The results of these studies indicate that flavour has a structural base that determines palatability. This base was found by analysis of dishes that have proven to be highly palatable. Six factors were identified which these dishes had in common. These factors were presumed to be critical for success. The CSFs were tested in a tasting which showed that 'CSF dishes' were not only preferred, but also best liked, despite the fact that variants of the CSF dishes were optimal, except for one or two CSFs. The CSFs that were formulated can therefore be considered to be drivers of liking and palatability, which make them relevant to food professionals.

Specialty dishes were analysed that are known to be highly appreciated when served in restaurants. It is important to note that their popularity is principally based on their flavour. One may argue that the reputation of a prominent chef or the atmosphere of a reputed restaurant will positively influence the flavour perception of the dishes served. Yet these influences will apply to all menu items and not just to the specialty dishes alone. It is more likely to be the other way around: the renown of the restaurant is acquired as a result of the quality of the specialty dishes. Extrinsic factors are therefore limited to their description on the menu, which must be accurate and can be promising and surely raises an expectation. After being selected and presented to the guest, the appearance of the dish can also be considered to be an extrinsic factor.

The results are based on free choices and subsequent descriptions of dishes by professional chefs. No sweet dishes, desserts, were mentioned and therefore the question should be addressed as to how this affects the results. It is likely that this influence is only marginal. First, in the analysis similarities on the macro level were looked for and consequently the CSFs are formulated at that level. Next, if the CSFs are considered in regard to desserts there are few differences to be expected. Expectation should still be met, smells should also be appetizing (although in cold dishes this influence will be less), the balance of flavours components is still important, the mouthfeel mix of hard and soft textures will also apply, just as the richness of flavour will also apply. The only factor that is likely to be of little influence is the umami factor. Generally, monosodium glutamate (MSG) is not used for sweet products (Yamaguchi \& Nonimiya 2000). Therefore it is pre- 
sumed that in general the CSF will apply to desserts as well.

It is believed that although the CSFs were formulated based on specialty restaurant dishes, they will apply to flavour in general, both for foods that are produced traditionally and industrially. However, further research on this subject is encouraged to verify the CSFs that were formulated. In the verification of the CSFs it was concluded that all factors should be present in a flavour to achieve a maximum result. Study 2 showed that both palatability and preference go down if one of the CSFs is eliminated. Nevertheless, this result may not be interpreted in the sense that there is only room for foods that fully comply with the CSFs. If foods are consumed functionally, or without specific intentions, hedonics is not really an issue. If, on the contrary, foods are meant for enjoyment, the CSFs become increasingly relevant and will enhance the chance of pleasure.

In relation to the different CSFs:

1 Expectation and palatability. A first prerequisite in liking a flavour is that it fits expectation. Sensory evaluation generally focuses on the intrinsic flavour components. However, the results of this study underline the importance of extrinsic factors. The name, image, packaging, advertising and promotion predispose the consumer to purchase, while product sensory attributes confirm liking and may determine repeat purchases. The package and name of a product are not just a source of brand identification, product category identification and product positioning; they actually are the product in virtual reality. They provide all the information needed for a decision on trial or repeat (Angeli 1995). Products should therefore convey their sensory character by extrinsic factors in such a way that the generated consumer expectations will be met. If the flavour and sensory expectations are not confirmed, the likelihood of product success in the targeted market is poor (Poulsen et al. 1996; Murray \& Delahunty 2000; Lesschaeve et al. 2001). Food companies must therefore be extremely careful in their choice of marketing claims to ensure that any information, product comparisons or category schemata be accurate in terms of the product's ability to match the claims when seeking to introduce novel foods into the marketplace (Tuorila et al. 1998).

These extrinsic aspects of food are likely to be more important than thought. Our study shows a significant influence of situational conditions in regard to flavour appreciation. The description of the food on the menu or otherwise should be such that choices can be made appropriately. This holds especially for the naming of fresh or ripe flavour notes. If the food has been chosen before and is re-chosen, then the expectation is influ- enced by the recollection of the previous experience, which implies that once a food has a certain name, it is closely related to its flavour. Changes in either the name or the flavour of a successful product will prove to be detrimental.

2 Smell and palatability. Much of what we call taste is in fact registered through the olfactory system. Smell is a major contributor to flavour richness, which implies that the flavour of a food product owes its depth and variability to smell. In the human neural anatomy there is a high level of functional connectivity between olfaction and the limbic system of the brain, which also processes emotions and memories. It is therefore plausible that of the intrinsic flavour components, smell is potentially the most important contributor to pleasure and palatability.

A reverse argument that shows the importance of smell in flavour is seen in the decline of olfactory capabilities of older people, which tends to begin around 60 years of age and becomes more severe in persons above 70 years of age. The enjoyment of eating is reported to go down, potentially leading to inadequate dietary intake (Brand et al. 2001). One study involving elderly people showed that when the smell of food was enhanced, natural intake increased (Schiffman 2000).

Certain odours have the potential to arouse and increase appetite. A good example is the specific aroma of the Maillard reaction as in roasting meat, coffee beans or almonds, and the baking of bread and cakes (Martins, et al. 2001).

3 Balance of gustatory flavours and palatability. In food product development it is beneficial to distinguish consumer segments and to consider the drivers of liking within such a segment. An inverted U-shape curve characterizes the typical course of preference. There is a certain optimum, making dosage crucial in flavour composition. Different consumer segments are likely to have different optimum levels of preference in the inverted U-curve. (Moskowitz \& Krieger 1998). Too little is almost as bad as too much. Although in some cases, like salt, components can easily be added to suit individual preference. The right dose of a certain component is food-dependant. A salad is expected to be fresh and acidic, and a cake is expected to be sweet. If it is acidic, palatability is questionable.

Of all basic flavour components there is a general misconception about bitter. Many chefs consider bitter an essential element as it makes food 'lighter' and more interesting. This is also illustrated by the food products that are universally popular: beer, chocolate, coffee, tea and wine. In all of these products bitter is markedly present. At the same time in sensory literature, bitter is reported to be a negative component that people do not 
like. How does this relate to the popularity of foods in which bitter is strongly present?

Another misconception involves sweetness. It is the most popular of the basic taste elements and the use of sugar, for example, tends these days to be exaggerated, making certain foods (e.g. mayonnaise, and salad dressing) sweeter and therefore less typical.

4 Umami and palatability. The results of this study confirm the importance of umami in relation to palatability. Some investigators argue that umami or glutamic flavour is an individual basic flavour, next to the basic four (sweet, salty, acidic, and bitter). It is therefore often referred to as the 'fifth basic taste'. The name and the scientists that discovered umami are Japanese, but as a flavour component umami has no specific relation with Asian cuisine. In fact it is a new word for an old flavour component that has always been valued as important. Umami does not itself have a distinct taste. In reports it is called 'brothy', 'savory' or 'meaty'. Depth and fullness are also mentioned. Moreover, umami gives a strong aftertaste. An agreeable aftertaste is an important determinant of the overall pleasantness of a meal. When translated from Japanese, umami means 'delicious' (Fuke \& Ueda 1996; Bellisle 1999).

Umami seems hard to identify and its existence is in the realm of debate. Yet many reports consider it to be the flavour of glutamic acid. This amino acid is a major constituent of food proteins and is naturally present in most foods. Best known is the sodium salt of glutamic acid, MSG, which is widely used in the food industry. Next to glutamate, $5^{\prime}$-ribonucleotides also contribute to umami taste: inosinate (inosine monophosphate) is found primarily in meat, guanylate (guanosine monophosphate) is more abundant in plants and mushrooms, whereas adynalate (adenosine monophosphayte) is found in fish and shellfish. There is a strong taste synergism between MSG and nucleotides. In many of the dishes analysed in study 1 , the ingredients used contributed to umami (Table 2) (Fuke \& Ueda 1996; Bellisle 1999; Yamaguchi \& Nonimiya 2000).

It is not quite clear how umami substances increase palatability, yet many reports show that they do (e.g. Bellisle 1999; Schiffman 2000). Umami also influences the perception of other 'basic' flavours. MSG increases the perception of saltiness, which implies that the actual amount of salt used can be lower in combination with MSG. MSG reduces the perception of sourness and bitterness, and has no apparent influence on the perception of sweetness. Preference for umami is likely to be innate - just as it is for sugar and fatty acids - as breast milk is rich in glutamic acid.

5 Mouthfeel and palatability. Crispness is associated with freshness. For example, within a relatively short time the crispness is gone in the crust of freshly baked bread, grilled steak, toast, French fries or even a salad. As soon as it is gone, these products have lost much of their appeal (Duizer 2001). In our study this effect was clearly demonstrated in the beef dishes, where the traditional preparation scored high.

As far as soft textures are concerned, fat is an important factor. Foods owe much of their flavour to fat. Fats serve a variety of functions. In some cases fat contributes a desirable mouthfeel or texture, in others fat enhances the flavour. Both influences contribute to palatability and liking, which is demonstrated by the abundance and popularity of high-fat foods. The negative consequence is that these foods are often over-consumed, leading to chronic diseases like obesity (Astrup et al. 2000). There are reports that there is an additional 'basic' taste for selected fatty acids. Such a new taste system could - at least to some extent - explain the positive human response to fat (Rolls et al. 1999; Bray 2000). For a food product or a dish to be successful though, the softness in whatever textural form apparently needs to be compensated by textures that have 'bite', according to the professional chefs interviewed. 6 Flavour richness and palatability. It is conceivable that this result is biased by the design of the study. Palatable, but non-complex dishes and flavours are not to be expected on the menu of exclusive restaurants. The guests of these restaurants are often in a certain frame of mind: relaxed and enjoying themselves - ideal circumstances to savour complexity. Earlier the influence of situational aspects on preference was mentioned: flavour profiles that are fresh and slightly acidic fit warm weather. The perception of complexity is also likely to be situational, as it requires rest. The relaxed atmosphere in top restaurants is therefore an important ingredient in the overall enjoyment of the food. In other senses this phenomenon is known as well. Therefore, there is a risk that the results on this point are biased by the chosen research format. Further studies are needed to address this issue.

\section{The backbone of palatability}

The CSFs of flavour are an attempt to formulate the factors that constitute palatability. It is important to note that the CSFs do not dictate how a food product should be made, and also do not impair creativity. The chef that was instructed to compose dishes based on the CSFs, had no problem in doing so; they served as guidelines. CSFs make flavour visible, and are as such useful in modifying existing products or formulating new ones. Up to now the fundamentals of palatability have not been formulated and the search for them may well have been neglected. Without a solid backbone, cooking and food-product development can easily be 
reduced to the character of 'cook and look'. We have not studied the causes of the high failure rate of many industrial food products but the absence of knowledge of the fundamentals may well be part of the explanation.

According to Cardello (1995), food quality can be considered both the most well-defined and the least well-defined concept in the food industry today. Food scientists or professional chefs are likely to define food quality from a product point of view. This definition does not necessarily correspond with consumer opinion. For commercial food products, it is essential that a product has a high quality from a consumer point of view. Earlier we noted that palatability is by definition related to food products and that it is a strong driver of liking, which is defined as the affective consumer response. A driver of liking can be defined as a product characteristic (sensory attribute) which, when changed, affects liking (Moskowitz \& Krieger 1998). In this respect the CSFs may prove to be an asset to sensory science. For commercial food companies, restaurants included, it is essential to know the 'drivers' of product acceptance.

There may be an interesting analogy with architecture, art, music and biology. In all of these areas the mathematical rule of the golden section has been proven to be applicable. It is the natural order with its harmonious proportions. In previous ages it was called the proportio divina, divine proportion. Some architects (le Corbusier), painters (Leonardo da Vinci) and sculptors (Michelangelo) are known to have actively used the golden section in their compositions (Lipovetsky \& Lootsma 2000). But it has also been found to apply in the structure of musical compositions (Bach and Mozart), in the ratios of harmonious sound frequencies, in the dimensions of the human body and in the structure of plants. Palatability in taste is comparable to 'beauty' in art. The ancient Greeks had the same word, techne, for both 'art' and 'technique'. Art was defined as 'the right way of making things'. In all art, technique is essential. There may be technique without art, but there is no art without technique (Hegarty \& O'Mahony 2001).

In conclusion, formulating CSFs can be seen as a first step in getting a better understanding of flavour and the components that drive liking. The chosen research format was based on a different orientation than traditional sensory research. We focussed on actual consumers eating real foods in real dining situations. This approach is essential to getting a better understanding of taste as a sense and all concepts that are related to it. The results show that the palatability of food is not a coincidence. It is a predictable outcome when the CSFs of food are present. The formulated CSFs will help chefs in the development of new dishes and improvement of existing ones. An interesting prospect for future research is to investigate whether these factors apply to industrially produced foods and in other cultures.

\section{References}

Abdi H (2002). What can cognitive psychology and sensory evaluation learn from each other? Food Quality and Preference 13:445-51.

Angeli P (1995). Thinking out of the box: a new approach to product development. Business Horizons MayJune:18-22.

Astrup A, Grunwald GK, Melanson EL, Saris WHM (2000). The role of low-fat diets in body weight control: a metaanalysis of ad-libitum dietary interveillon studies. International Journal of Obesity 24:1545-52.

Bellisle F (1999). Glutamate and the umami taste: sensory, metabolic, nutritional and behavioral considerations. A review of the literature published in the last 10 years. Neuroscience and Biobehavioral Reviews 23:423-38.

Brand G, Millot J-L, Henquell D (2001). Complexity of olfactory lateralization processes revealed by functional imaging: a review. Neuroscience and Biobehavioral Reviews 25:15966.

Bray GA (2000). Afferent signals regulating food intake. Proceedings of the Nutrition Society 59:373-84.

Cardello AV (1995). Food quality: relativity, context and consumer expectations. Food Quality and Preference 6:16370.

Cardello AV, Schutz H, Snow C, Lesher L (2000). Prediction of food acceptance, consumption and satisfaction in specific eating conditions. Food Quality and Preference 11:20116.

De Castro JM (2000). Eating behavior: lessons from the real world of humans. Nutrition 16:800-13.

Duizer L (2001). A review of acoustic research for studying the sensory perception of crisp, crunchy and crackly textures. Trends in Food Science \& Technology 12:1724.

Fuke S, Ueda Y (1996). Interactions between umami and other flavor characteristics. Trends in Food Science \& Technology 7:407-11.

Hegarty JA, O’Mahony GB (2001). Gastronomy: a phenomenon of cultural expressionism and an aesthetic for living. International Journal of Hospitality Management 20:313.

Lesschaeve I, Norris LN, Lee TH (2001). Defining and targeting consumer preferences. 11th Australian Wine Industry Technical Conference Proceedings. October 7-11.

Lipovetsky S, Lootsma FA (2000). Generalized golden sections, repeated bisections and aesthetic pleasure. European Journal of Operational Research 121:213-16.

Martins SIFS, Jongen WMF, Van Boeckel MAJS (2001). A review of Maillard reaction in food and implications to kinetic modeling. Trends in Food Science \& Technology 11:364-73

Michelin SA (2002). Michelin Guide 2002. édition Benelux: Brussels.

Moskowitz H, Krieger B (1998). International product optimization: a case history. Food Quality and Preference 9:443-54. 
Murray JM, Delahunty CM (2000). Mapping consumer preference for the sensory and packaging attributes of Cheddar cheese. Food Quality and Preference 11:41935 .

Ninomiya K (1998). Natural occurrence. Food Reviews International 14:177-213.

Poulsen CS, Juhl HJ, Kristensen K, Bech AC, Engelund E (1996). Quality guidance and quality formation. Food Quality and Preference 7:127-35.

Rolls ET, Critchley HD, Browning AS, Hernadi I, Lenard L (1999). Responses to the sensory properties of fat of neurons in the primate orbifrontal cortex. Journal of Neuroscience 19:1532-40.

Schiffman SS (2000). Intensification of sensory properties of foods for the elderly. Journal of Nutrition 130:927S30 s.

The Monell Connection (2000). Newsletter from the Monell Chemical Senses Center, Spring 2000.

Tuorila HM, Meiselman HL, Cardello AV, Lesher LL (1998). Effect of expectations and the definition of product category on the acceptance of unfamiliar foods. Food Quality and Preference 9:421-30.

Yamaguchi S, Nonimiya K (2000). Umami and food palatability. Journal of Nutrition 130:921S-6S.

Yoshida Y (1998). Umami taste and traditional seasonings. Food Reviews International 14:213-47.

\section{Appendix I}

\section{Questionnaire chefs}

Name chef:

Name dish:

Presentation:

Flavor profile:

- Mouthfeel:

- Flavor intensity:

- Fresh flavor tones:

- Ripe flavor tones:

Seasonality of the dish:

Regionalism of the dish:

Consumer price:

- less than 10 Euro

- between 10 and 25 Euro

- more than 25 Euro

How long has the dish been on the menu (min. 3 years): Was it immediately successful?

Has the dish been changed over time?

What is your explanation for its success?

\section{Appendix II}

Tasting forms

Round 1. Dishes

Fried prawn with Noilly Prat sauce and lobster oil, potato mousseline and green asparagus

Warm carpaccio of prawn with saffronated potato, slices of asparagus and lobster oil

Grilled prawn with lobster sauce, morels, saffronated potato mousseline

Round 2. Dishes

Sautéed turbot with aniseed-mushrooms, and chanterelles, braised shallots, celeriac chips and truffle sauce

Sautéed turbot with aniseed-mushrooms and a mousse of shallots, celeriac and chanterelles

Sautéed turbot with mousse of fennel, braised fennel, aniseed-mushrooms, shallots and fennel sauce

Round 3. Dishes

Preference 1, 2 or 3 Judgment Scale 1-10 Order of eating 1,2 or 3

Preference 1,2 or 3 Judgment Scale $1-10$

Order of eating 1,2 or 3

Preference 1, 2 or 3 Judgment Scale 1-10 Order of eating 1,2 or 3

Roasted fillet 'Rossini'

Poached fillet with goose liver, fried egg and vegetables

Tartare of fillet with goose liver and poached egg 
Copyright of Food Service Technology is the property of Blackwell Publishing Limited and its content may not be copied or emailed to multiple sites or posted to a listserv without the copyright holder's express written permission. However, users may print, download, or email articles for individual use. 